\title{
Implementation Challenges to Using Respondent-Driven Sampling Methodology for HIV Biological and Behavioral Surveillance: Field Experiences in International Settings
}

Lisa Grazina Johnston • Mohsen Malekinejad •

Carl Kendall · Irene M. Iuppa - George W. Rutherford

Published online: 16 December 2008

(C) Springer Science+Business Media, LLC 2008

\section{Erratum to: AIDS and Behavior}

\section{DOI: 10.1007/s10461-008-9413-1}

On page S132, first full paragraph, the statement "whereby those with larger network sizes have a smaller probability of selection and vice versa" should be corrected to read "whereby those with larger network sizes have a larger probability of selection and vice versa". This correction is consistent with the conclusions from the study.

The online version of the original article can be found under doi:10.1007/s10461-008-9413-1.

L. G. Johnston $(\bowtie) \cdot$ C. Kendall

School of Public Health and Tropical Medicine,

Tulane University, New Orleans, LA, USA

e-mail: 1sjohnston.global@gmail.com

L. G. Johnston

13 Via Plaza Nueva, Santa Fe, NM 87507, USA

M. Malekinejad · I. M. Iuppa - G. W. Rutherford Global Health Sciences, University of California, San Francisco, San Francisco, CA, USA

\section{Malekinejad}

School of Public Health, University of California,

Berkeley, Berkeley, CA, USA 